\title{
Segond Fracture - Rare Presentation in A Teenager
}

\author{
Patricia R*, Mafalda B and Delfin T \\ Hospital Dona Estefânia CHLO, Lisboa, Portugal
}

Submission: April 28, 2017; Published: May 12, 2017

*Corresponding author: Patricia R, Hospital Dona Estefânia CHLO, Lisboa, Portugal.

\begin{abstract}
Segond fracture is a rare lesion in adolescents, resulting from rotational forces in the knee. It is considered highly suggestive of anterior cruciate ligament (ACL) lesion in the adult population. There are few cases of Segond fractures in adolescent in literature. We present a case of a
\end{abstract} Segond fracture with parcial ACL lesion, in an adolescent.

Keywords: Segond; teenager; ACL tear

\section{Introduction}

First described in 1879 by Dr. Paul Segond as the lateral capsular sign and then named Segond fracture - an avulsion fracture of the midportion of lateral tibial plateau, corresponds to a lateral knee injury and is often associated with antero lateral rotatory instability of the knee being considered as a pathognomonic sign of other lesions, such as ACL rupture (partial or complete) in $75-100 \%$ of case, in the adult population. It is a rare condition in children and adolescents and in these cases it is usually isolated or associated with avulsion of the tibial spines, being rare the intra substance rupture of the ACL. This fracture pattern results from varus and internal rotational forces applied to the knee, usually during sports.

\section{Case Report}

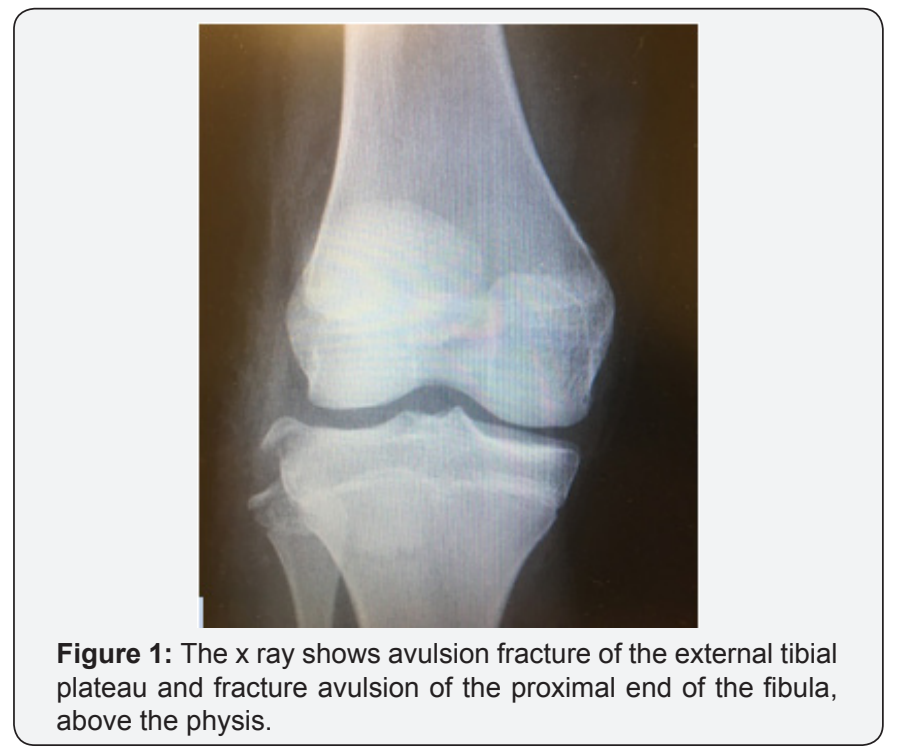

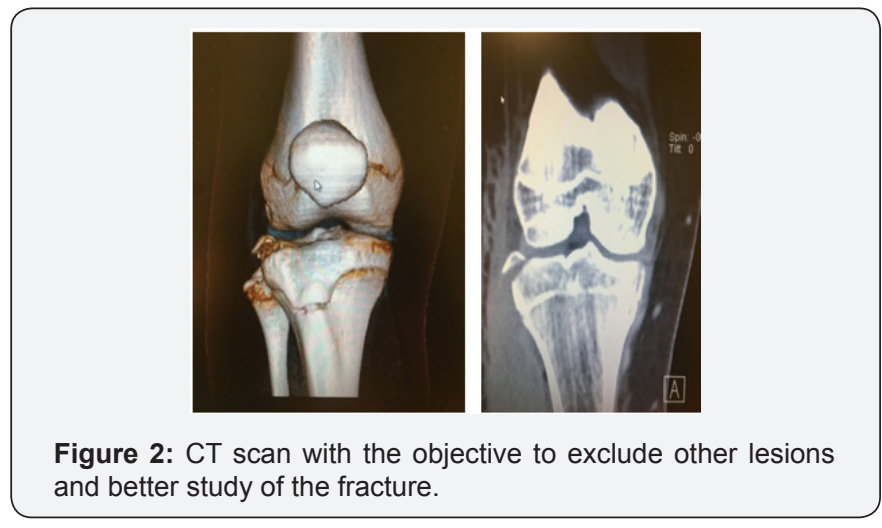

We present a case of a 14-year-old girl who suffered a sports accident during a jump from a bench while practicing parkour, which caused a rotational movement in the right knee. She was evaluated in the emergency department and the clinical evaluation showed difficulty in walking and mobilizing the knee, knee joint effusion. Because she was in pain it was not possible to evaluate ligament stability and meniscal tests. X-ray showed avulsion fracture of the external tibial plateau and fracture avulsion of the proximal end of the fibula, above the physis (Figure 1). CT was performed to evaluate possible intra-articular lesions and better study of the lesion (Figure 2). Surgical treatment was decided. We evaluated and tested the knee for instability, under anesthesia and great antero-posterior (positive drawer test) and lateral instability was verified [1-3].

Arthroscopy was performed to assess ligament and meniscal integrity. Partial ACL rupture and LLE avulsion were observed on the lateral face of the external tibial plateau, without associated meniscal lesions. An external approach was then performed 
and a harpoon ligament fixation was performed (Figure 3). At the end of the surgery, there was slight ligament instability, and conservative treatment was decided in relation to partial ACL rupture. After the surgery, the patient had indication for nonweight bearing and knee orthosis blocked in extension and with varus-valgus block.

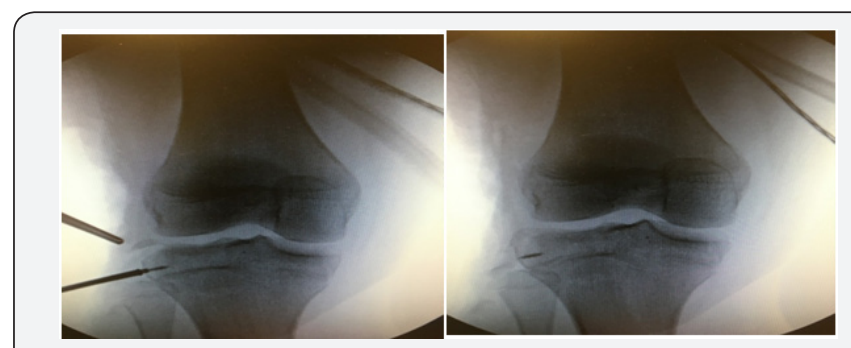

Figure 3: Intra operative $\mathrm{x}$ ray showing the reduction of the fracture with a harpoon.

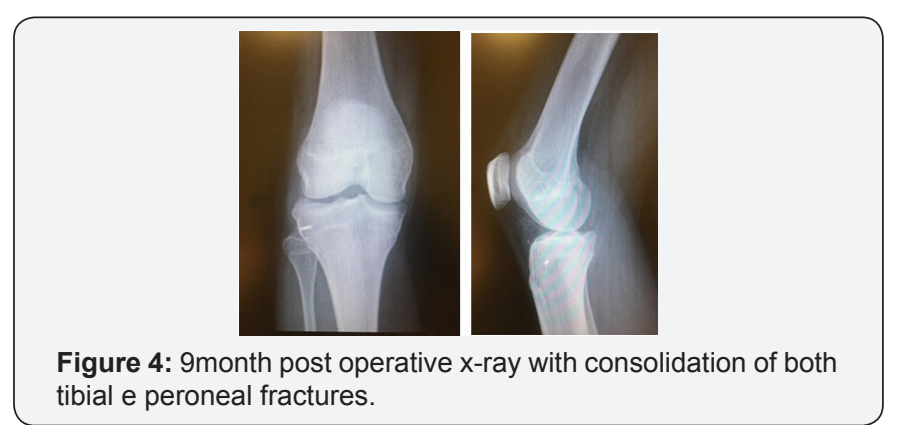

Initiated range of motion at 2 weeks, initially limited to $30^{\circ}$ for 2 weeks, then increased to $60^{\circ}$ and started $0-90^{\circ}$ at 6 weeks. In this phase also started protected progressive weight bearing. There was a fracture consolidation at follow-up at 9 months (Figure 4), without rotational instability, without lateral instability and negative meniscal tests.

She resumed sporting activity at 9 months.

\section{Discussion}

This type of fracture is rare in our clinical practice and is therefore an interesting case. There is some differences between the association of Segond fracture and ACL tear in adult versus pediatric population. Because of the lack of studies (cadaveric, anatomic or surgical) in the pediatric population we can only hypothesize that in the pediatric knee the ligaments are stronger (as in other articulations ligaments are stronger than the physis), and therefore it is easier to avulse the spine of the tibia or avulse a small fragment prior to ligament rupture.

The decision to surgical treatment was made by the presence of a great antero-posterior and lateral instability. Although the fracture itself is small, the extensive ligamentous injury associated with it usually requires surgical intervention. After fracture fixation, the stability was again tested, showing an increase in stability, despite the partial rupture of the ACL. The risk of not treating this type of injury is essentially the chronic instability of the knee, mainly the rotational instability.

\section{References}

1. Segond P (1879) Recherches cliniques etexérimentalessurlesépanchementssanguinsdugenou par entorse. ProgMed (Paris)b 1879: 1-85.

2. Jacob Ringenberg, David Sealy, Robert Tiller (2015) Isolated Segond Fracure in a Pediatric Patient. Phys Sportsmed 43(2): 188-191.

3. Arneja SS, Furey MJ, Alvarez CM, Reilly CW (2010) Segond fractures: Not necessarily pathognemonic of anterior cruciate ligament injury in the pediatric population. Sports Health 2: 437-439.

\section{Your next submission with Juniper Publishers will reach you the below assets}

- Quality Editorial service

- Swift Peer Review

- Reprints availability

- E-prints Service

- Manuscript Podcast for convenient understanding

- Global attainment for your research

- Manuscript accessibility in different formats

( Pdf, E-pub, Full Text, Audio)

- Unceasing customer service

Track the below URL for one-step submission https://juniperpublishers.com/online-submission.php 